\title{
Breathlessness in liver disease: A case of hepatopulmonary syndrome 䇺
}

\author{
Authors: Ruth Porther, ${ }^{A}$ Gavin Ross ${ }^{B}$ and Subramaniam Nagasay ${ }^{C}$
}

\begin{abstract}
Hepatopulmonary syndrome (HPS) is often not considered as a cause of breathlessness in patients with liver cirrhosis. It consists of a triad of liver disease, intrapulmonary shunting and hypoxaemia. Here we discuss HPS in a patient presenting with acute on chronic breathlessness and typical features of orthodeoxia and platypnoea. Evidence of intrapulmonary shunting on imaging was essential to making the diagnosis, which carries a poor prognosis and was an urgent indication for liver transplantation.
\end{abstract}

KEYWORDS: Cirrhosis, hypoxaemia, platypnoea, orthodeoxia, hepatopulmonary syndrome

\section{Case presentation}

The patient was a 58-year-old female, with known liver cirrhosis, portal hypertension and varices secondary to previous alcohol excess and obesity. She was breathless for 2 months then became acutely breathless with low oxygen saturations of $75 \%$ in primary care so was admitted for assessment. She also suffered diarrhoea and vomiting for 2 days prior with no symptoms of upper gastrointestinal (GI) bleeding or encephalopathy.

The patient had no background respiratory disease or venous thromboembolism (VTE), and never smoked, although she kept a budgerigar for the last 15 years. Trial of salbutamol made no difference and spirometry in primary care was unremarkable. Body mass index (BMI) was 25 (weight $64 \mathrm{~kg}$, height $160 \mathrm{~cm}$ ).

In the emergency department, she was afebrile, oxygen saturation $86 \%$ on air, respiratory rate 24 breaths/min, pulse 93 beats/min and blood pressure $82 / 45 \mathrm{mmHg}$. She had clubbing with extensive spider naevi on the upper torso. On examination, her chest was clear. There were no signs of ascites, encephalopathy or postural blood pressure response.

Blood results were haemoglobin $114 \mathrm{~g} / \mathrm{L}$, white cell count $13.2 \times 10^{9} / \mathrm{L}$, MCV $83 \mathrm{fL}$, platelets $73 \times 10^{9} / \mathrm{L}$ (baseline 90 to 100 ), C-reactive protein $30 \mathrm{mg} / \mathrm{L}$, urea $6.3 \mathrm{mmol} / \mathrm{L}$, creatinine $144 \mu \mathrm{mol} / \mathrm{L}$.

Authors: ${ }^{\text {A }}$ linical fellow in general medicine, Withybush General Hospital, Haverfordwest, UK; ${ }^{B}$ specialty doctor in gastroenterology, Withybush General Hospital, Haverfordwest, UK; ' Consultant physician / care of the elderly, Withybush General Hospital, Haverfordwest, UK
Arterial blood gas results were fraction of inspired oxygen 0.24, $\mathrm{pH} 7.42, \mathrm{PCO}_{2} 2.9 \mathrm{kPa}, \mathrm{PO}_{2} 10.0 \mathrm{kPa}$, lactate $3.7 \mathrm{mmol} / \mathrm{L}$, bicarbonate $14.3 \mathrm{mmol} / \mathrm{L}$. The electrocardiogram was unremarkable with no evidence of right heart strain. Chest $x$-ray showed no evidence of pulmonary congestion, effusion or atelectasis. Transthoracic echocardiogram (TTE) showed normal biventricular function.

We did not employ contrast-enhanced TTE ('bubble echo') as it was unavailable in our rural hospital.

\section{Diagnosis}

Differential diagnoses of dyspnoea in chronic liver disease include large ascites and diaphragmatic splinting, hepatic hydrothorax, anaemia secondary to GI haemorrhage. Uncommon causes include cirrhotic cardiomyopathy, portopulmonary hypertension (PPH) and hepatopulmonary syndrome (HPS). Patients can have coexistent cardio-respiratory conditions such as pneumonia, congestive cardiac failure, obstructive sleep apnoea, pulmonary thromboembolic disease, chronic obstructive airway disease and interstitial lung disease (ILD).

The patient was unlikely to be experiencing most of above since she had normal BMI and cardiorespiratory examination, no ascites or peripheral oedema and unremarkable chest $x$-ray and TTE. It was important to rule out pulmonary embolus given sudden worsening of symptoms and unexplained hypoxia. ILD was considered due to contact with a budgerigar. Lastly, the possibility of HPS was considered given her background of cirrhosis and varices.

\section{Initial management and prognosis}

Though pulmonary embolism was our first diagnosis, computed tomography (CT) pulmonary angiogram (PA) was postponed due to acute kidney injury (risk of contrast-induced nephropathy). She was, however, started on a renal-adjusted dose of therapeutic enoxaparin with intravenous hydration. High-resolution CT showed widespread dilatation of pulmonary veins but no ILD. It also confirmed severe liver cirrhosis with portal hypertension and huge porto-systemic collaterals.

After re-visiting the diagnosis, oxygen saturation on air showed marked postural difference (orthodeoxia) changing from 70\% sitting to $89 \%$ lying down and the patient also described symptoms of platypnoea (opposite of orthopnoea). The patient's regular gastroenterologist advised a nuclear medicine perfusion scan which showed 'strong evidence of HPS with the right-to-left shunt calculated at over 39\%' (see Fig 1). CTPA performed once renal function improved was negative and enoxaparin stopped. 


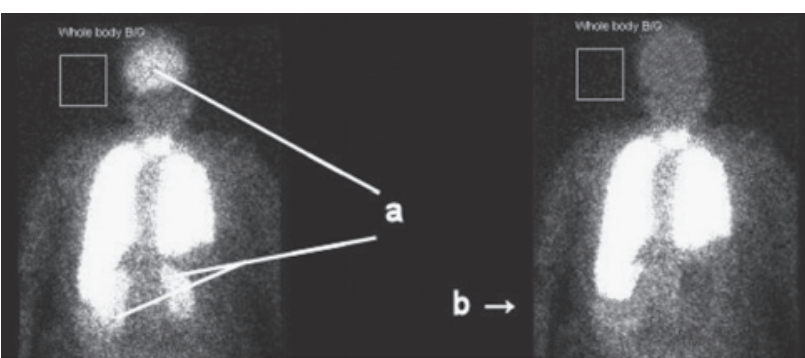

Fig 1. Nuclear medicine perfusion scan. (a) Nuclear medicine shunt study: Abnormal uptake of Tc99-labelled macroaggregated albumin in brain and kidneys. (b) Approximation of normal appearances.

\section{Case progression and outcome}

The patient was discharged with long-term oxygen. At the time of writing she was on the waiting list for a liver transplant.

\section{Discussion}

Liver cirrhosis and portal hypertension often leads to complications such as jaundice, ascites, hepatic encephalopathy, variceal bleeding, spontaneous bacterial peritonitis and HPS. HPS is a triad of liver disease, increased alveolar-arterial oxygen gradient and intrapulmonary vascular dilatation. The prevalence of HPS varies between 5 and $32 \%$.

Features of HPS predominantly manifest with dyspnoea and platypnoea. In such patients, evidence of orthodeoxia (highly specific for HPS) should be sought. ${ }^{2}$ Orthodeoxia is attributed to preferential perfusion of lung bases which causes greater functional shunting when upright. Spider naevi are often present and represent a cutaneous marker for intrapulmonary vascular dilatations. $^{3}$

HPS in patients with cirrhosis is a poor prognostic feature and, in a prospective study, ${ }^{4}$ was found to be an independent risk factor for survival. In this study, median survival of cirrhotic patients with HPS was shortened by $25 \%$ compared to those without. The pathogenesis of HPS remains unknown. The characteristic feature is microvascular dilatation in the pulmonary capillary bed which leads to ventilation-perfusion mismatch and failure of gas exchange.

In nuclear medicine imaging, technetium-99 labelled macroaggregated albumin can be administered intravenously and scintigraphic images analysed. In a normal subject, nearly all of the particles are trapped in the pulmonary capillary bed. If intrapulmonary vascular shunting is present, the particles can be seen lodged in the brain or renal capillaries (see Fig 1). Bubble echo is very sensitive in detecting pulmonary vascular dilatation and, hence, shunting. ${ }^{1}$

PPH mimics HPS but clinical examination reveals features of right heart failure. Its pathogenesis is incompletely understood and believed to be due to pulmonary vasculature endothelial

\section{Box 1. Summary of learning points}

Any breathless, hypoxic patient with cirrhosis should be checked for platypnoea and orthodeoxia at the bedside.

Hepatopulmonary syndrome is perhaps the least-recognised complication of cirrhosis.

Spider naevi represent a cutaneous marker for intrapulmonary shunting.

Hepatopulmonary syndrome is reversible and an indication for urgent liver transplantation.

injury. TTE may show evidence of right heart strain and pulmonary hypertension but this is confirmed with right heart catheterization studies.

Cirrhotic patients have deranged clotting and tendency to bleed, but also have increased risk of VTE. ${ }^{5}$ This should be ruled out when they present with unexplained hypoxaemia.

HPS can be reversed following transplant, although posttransplant prognosis is worse than that of patients without it. There is no role for transjugular intrahepatic portosystemic shunt insertion.

In the acute medical take, common causes for hypoxaemia need to be excluded before considering HPS, but recognition in cirrhotic patients is crucial so they can be considered in a timely manner for liver transplantation.

\section{Acknowledgements}

The authors wish to acknowledge the expert input of Dr Asheesh Vaishnavi, consultant physician and gastroenterologist (retired), Withybush General Hospital, Haverfordwest, UK.

\section{References}

1 Angeli P, Bernardi M, Villaneuva C et al. EASL Clinical Practice Guidelines for the management of patients with decompensated cirrhosis. J Hepatol 2018;69:406-60.

2 Seward JB, Hayes DL, Smith HC et al. Platypnoea-orthodeoxia: clinical profile, diagnostic workup, management and report of seven cases. Mayo Clin Proc 1984;59:221-31.

3 Lima BL, Franca AV, Pazin-Filho A et al. Frequency, clinical characteristics and respiratory parameters of hepatopulmonary syndrome. Mayo Clin Proc 2004;79:42-8.

4 Schenk P, Schöniger-Hekele M, Fuhrmann V et al. Prognostic significance of the hepatopulmonary syndrome in patients with cirrhosis. Gastroenterology 2003;125:1042-52.

5 Gulley D, Teal E, Suvannasankha A et al. Deep vein thrombosis and pulmonary embolism in cirrhosis patients. Digestive Diseases and Sciences 2008;53:3012-7.

Address for correspondence: Dr Ruth Porther, Hywel Dda University Health Board, Withybush General Hospital, Fishguard Road, Haverfordwest SA61 2PZ, UK.

Email: ruthporther@hotmail.com 